\title{
The validity of the non-exercise activity thermogenesis questionnaire evaluated by objectively measured daily physical activity by the triaxial accelerometer
}

\author{
Hidetaka Hamasaki ${ }^{1,2}$, Hidekatsu Yanai ${ }^{1 *}$, Masafumi Kakei ${ }^{2}$, Mitsuhiko Noda ${ }^{3}$ and Osamu Ezaki ${ }^{4}$
}

\begin{abstract}
Background: Physical inactivity is a major cardiovascular risk factor. Recently, we showed that non-exercise activity thermogenesis (NEAT) assessed by the self-reported questionnaire is favorably associated with metabolic risks in patients with type 2 diabetes. The purpose of the present study was to examine the validity of the questionnaire by comparing with objectively measured daily physical activity (PA) by using the triaxial accelerometer.

Methods: Daily physical activity level (PAL) of 51 participants (24 men and 27 women) with type 2 diabetes was measured by the triaxial accelerometer. At the same time, we evaluated their NEAT score using our original questionnaire modified from a compendium of physical activities.

Results: The NEAT score was significantly and positively correlated with PAL measured by the triaxial accelerometer $(r=0.604, P<0.001)$. PAL was also significantly and positively correlated with both the locomotive NEAT score and the non-locomotive NEAT score $(r=0.444, P=0.001$ and $r=0.526, P<0.001$, respectively).

Conclusions: The NEAT score measured by the self-reported questionnaire was highly correlated with PAL measured by the triaxial accelerometer. Our original NEAT questionnaire may be useful for evaluation of daily PAL in clinical practices.
\end{abstract}

Keywords: Physical activity, Non exercise activity thermogenesis, Accelerometer, Type 2 diabetes

\section{Background}

A sedentary lifestyle is a major cardiovascular risk factor [1] and daily physical activity (PA) is associated with a reduction in all-cause mortality and cardiovascular diseases (CVD) risk in patients with diabetes [2]. Only about 30\% of Japanese adults fulfill the recommended physical activity level (PAL) [3], therefore, it is important to understand whether daily PA including going to work, washing clothes and cleaning floors, defined as non-exercise activity thermogenesis (NEAT) [4] can improve CVD risk factors, or not $[5,6]$.

We have previously demonstrated that NEAT score determined by our original questionnaire is favorably

\footnotetext{
* Correspondence: dyanai@hospk.ncgm.go.jp

'Department of Internal Medicine, National Center for Global Health and Medicine Kohnodai Hospital, Chiba, Japan

Full list of author information is available at the end of the article
}

associated with insulin sensitivity, waist circumference, high-density lipoprotein cholesterol (HDL-C), blood pressure in patients with type 2 diabetes [7]. However, our study had the limitation that the NEAT score calculated with the self-reported questionnaire is subjective data and may not always represent the true NEAT. Here we investigated the correlation between the NEAT score and PAL measured by the triaxial accelerometer under free living conditions in patients with type 2 diabetes and confirmed the validity of our NEAT questionnaire.

\section{Methods}

Study participants

This study was approved by the Ethical Committee of the National Center for Global Health and Medicine (reference number NCGM-G-001212-00). All participants provided written informed consent. The participants studied were 
51 patients with type 2 diabetes without physical disability aged between 27 and 79 years old. Participants who engaged in active sports-like exercise and resistance training were excluded. Characteristics of the participants studied are shown in Table 1.

\section{Daily physical activity measurement by the triaxial accelerometer}

Daily PA was measured using the triaxial accelerometer (Active Style Pro HJA-350IT, Omron Co., Ltd, Kyoto, Japan), $74 \times 46 \times 34 \mathrm{~mm}$ and $60 \mathrm{~g}$ including batteries. Participants studied wore the accelerometer on the left side of the waist. Anteroposterior, mediolateral and vertical acceleration measurements were obtained during each physical activity at a rate of $32 \mathrm{~Hz}$ to 12-bit accuracy. Each of three signals from the triaxial accelerometer was passed through a high-pass filter with a cut-off frequency of $0.7 \mathrm{~Hz}$ to remove the gravitational acceleration component. The ratios of unfiltered to filtered total acceleration (TAU/TAF) and filtered vertical and horizontal acceleration (VAF/HAF) were calculated to determine the cut-off value for the classification of locomotive activities and non-locomotive activities including such as household and occupational activities, which resulted in almost $100 \%$ accurate demarcation for daily eleven different activities [8]. Furthermore, metabolic equivalent values (METs) determined by the triaxial accelerometer have been reported to be closely correlated with METs calculated by using energy expenditure (EE) measured by the indirect calorimetry $[8,9]$. Participants studied wore the

\section{Table 1 Participants characteristics}

\begin{tabular}{ll}
\hline Demographics & \\
\hline $\mathrm{N}$ & 51 \\
Sex (men/women) & $24 / 27$ \\
Age (years) & $58.5 \pm 12.3$ \\
Height (cm) & $160.7 \pm 8.7$ \\
Weight (kg) & $69.0 \pm 14.4$ \\
BMl (kg/cm²) & $26.7 \pm 5.2$ \\
\hline
\end{tabular}

Physiological parameters

\begin{tabular}{ll} 
PAL & $1.62 \pm 0.19$ \\
BMR (kcal/day) & $1344.1 \pm 268.5$ \\
\hline
\end{tabular}

Biochemical parameters

Fasting plasma glucose (mg/dl)

$123.5 \pm 25.9$

HbA1c (\%)

$6.7 \pm 1.0$

NEAT score

Locomotive activities

$19.5 \pm 4.0$

Non-locomotive activities

$43.7 \pm 9.7$

Total

$63.2 \pm 11.6$

Data are means \pm SD. BMI, body mass index; PAL, physical activity level; BMR, basal metabolic rate; NEAT, non-exercise activity thermogenesis. accelerometer on the left side of the waist for consecutive 7 days, and physical activities were recorded. Participants were requested to wear the accelerometer except under special circumstances such as sleeping, bathing and during aquatic activities. Activity data were stored on a minute-byminute basis and were downloaded to a personal computer before analysis. We excluded days in which participants did not wear the accelerometer for more than 8 hours from the data for analysis.

Basal metabolic rate (BMR) was estimated from multiple regression equation including age, sex, height and ideal body weight (IBW) as variables, the equation as follows: BMR $(\mathrm{kcal} /$ day $)=[(0.1283+0.0481 \times \mathrm{IBW}(\mathrm{kg})+0.0234 \times$ height $(\mathrm{cm})-0.0138 \times$ age $($ year $)-0.5473 \times$ sex coefficient (man: 1, woman:2)) $\times 2$ 293] [10]. Total energy expenditure (TEE) was calculated by manufactured regression equation using METs assessed by the triaxial accelerometer [9]. PAL was calculated by the following equation. PAL = TEE/BMR [11].

\section{Assessment of NEAT by using an original questionnaire}

After measuring daily PA by the triaxial accelerometer, we asked participants about their daily PA to evaluate NEAT, by using an original questionnaire which we have previously reported (Additional file 1) [7]. The questionnaire consisted of 11 question items about locomotive activities and 25 question items about non-locomotive activities. Table 2 showed questionnaire items about locomotive and non-locomotive activities, and also predicted METs by each activity in our NEAT questionnaire $[7,12]$. We evaluated each questionnaire item with a score of 1 to 3 points in order of levels of daily PA and then added up the scores to determine the NEAT score.

\section{Statistical analysis}

Statistical analysis was performed using SPSS version 19 (IBM Co., Ltd, Chicago, USA). All values were expressed as the mean \pm standard deviation (SD). Pearson's correlation coefficient was calculated in order to analyze the association of the NEAT score with PAL. P value $<0.05$ was considered to be statistically significant.

\section{Results}

In the present study, the NEAT score was significantly and positively correlated with PAL measured by the triaxial accelerometer $(r=0.604, \mathrm{P}<0.001$; Figure 1$)$. PAL was also significantly and positively correlated with both the locomotive NEAT score and the non-locomotive NEAT score $(\mathrm{r}=0.444, \mathrm{P}=0.001$ and $\mathrm{r}=0.526, \mathrm{P}<0.001$, respectively; Figure 2). Both the locomotive NEAT score and the nonlocomotive NEAT score were significantly correlated with the whole NEAT scores $(\mathrm{r}=0.612, \mathrm{P}<0.001$ and $\mathrm{r}=0.946$, $\mathrm{P}<0.001$, respectively; Figure 3). 
Table 2 Locomotive and non-locomotive activities, and predicted METs by each activity in our NEAT questionnaire

\begin{tabular}{llll}
\hline Locomotive activities & & \multicolumn{2}{l}{ Non-locomotive activities } \\
Specific activities & Predicted METs & Specific activities & Predicted METs \\
\hline Commuting on foot & 4.0 & cleaning & $2.5-3.8$ \\
Walking a lot while working & 3.5 & cooking & 3.5 \\
Getting on a train or a bus & 1.3 & washing the dishes & 3.3 \\
Using stairs & 3.5 & ironing & 1.8 \\
Shopping for food & 2.3 & cleaning the bath & 2.3 \\
Taking the garbage out & 2.5 & cleaning the garden & 4.0 \\
Playing with children outside & $3.5-5.8$ & weeding or gardening & 3.5 \\
Going for a walk & 3.5 & watering plants & 1.5 \\
& & feeding pets & 2.5 \\
& & looking after children & $2.0-3.0$ \\
& & looking after the elderly & $2.3-4.0$ \\
\end{tabular}

NEAT, non-exercise activity thermogenesis; METs, metabolic equivalent values.

Our previous study showed that the NEAT score was significantly and inversely associated with serum insulin levels, suggesting a beneficial association of NEAT with insulin sensitivity in all participants [7] (Table 3). The NEAT score was inversely associated with waist circumference, and also was positively associated with HDL-C level in women [7] (Table 3). However, a beneficial association of NEAT with waist circumference and HDL-C was not observed in men.

There were no differences in PAL and locomotive NEAT score between men $(1.59 \pm 0.15$ and $20.4 \pm 3.9$, respectively) and women $(1.64 \pm 0.22$ and $18.6 \pm 3.9$, respectively). However, the whole NEAT score and non-locomotive NEAT score were significantly higher in women $(66.9 \pm 12.7$ and $48.3 \pm 9.2)$ compared with those in men $(59.0 \pm 8.6$ and $38.6 \pm 7.4 ; \mathrm{P}=0.026$ and $\mathrm{P}<0.001$, respectively).

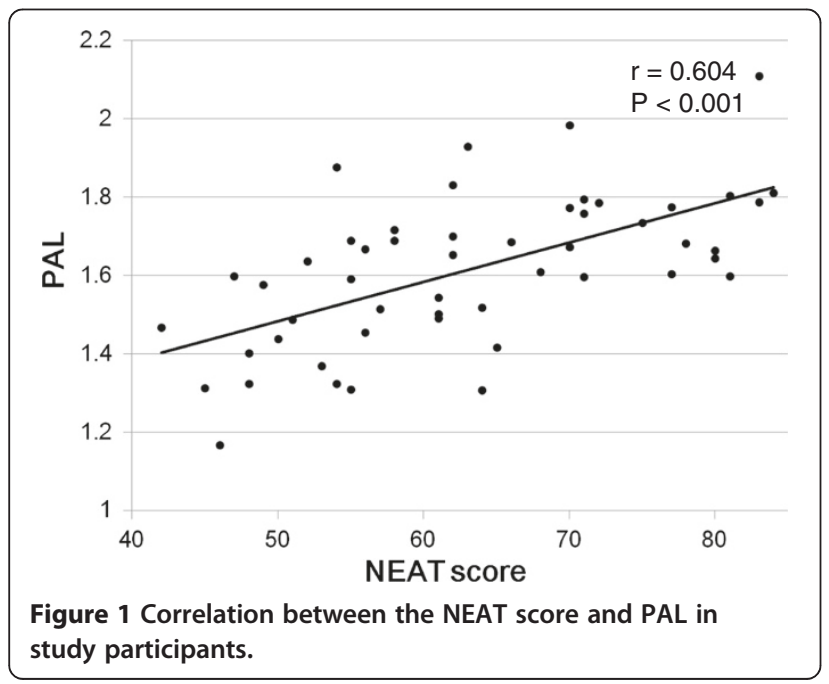

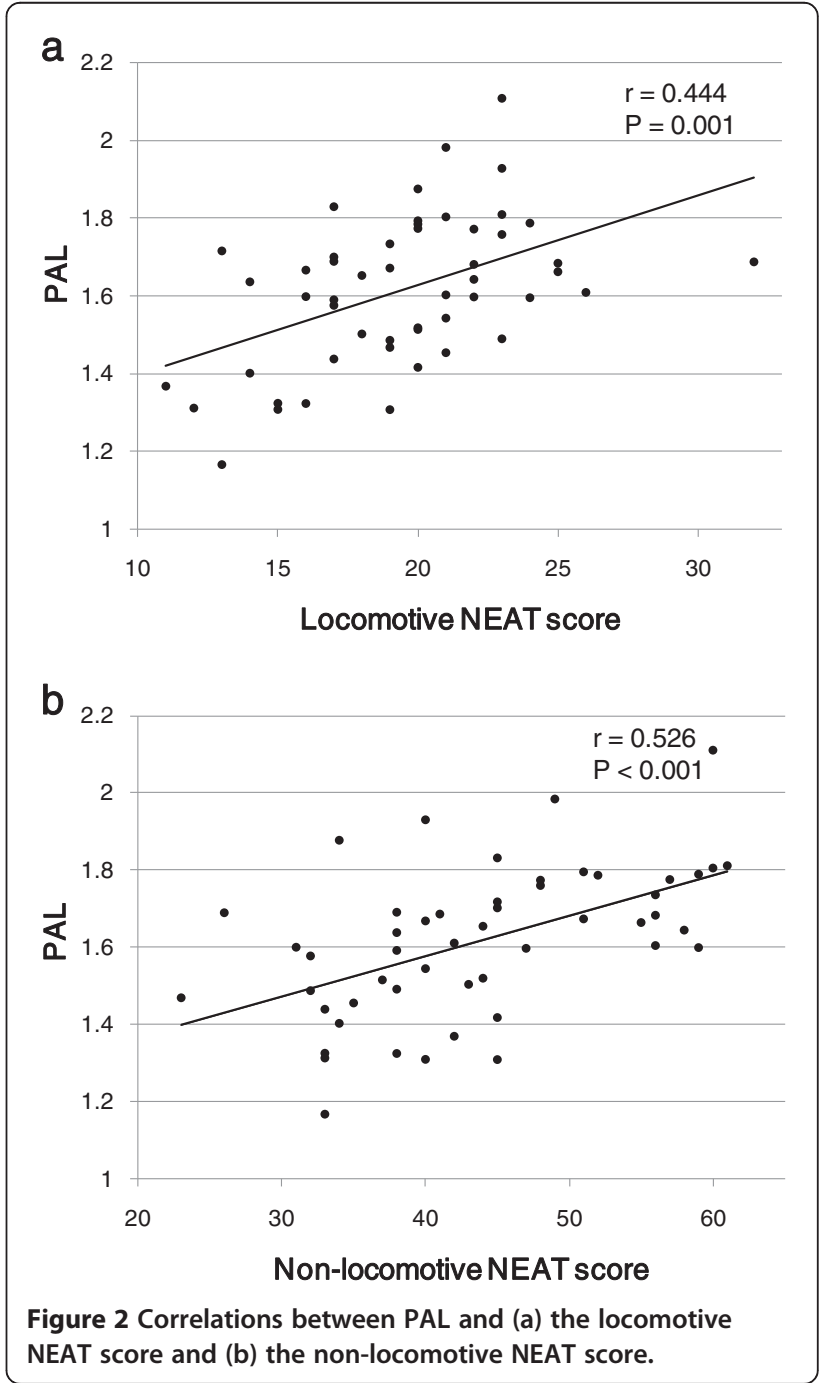




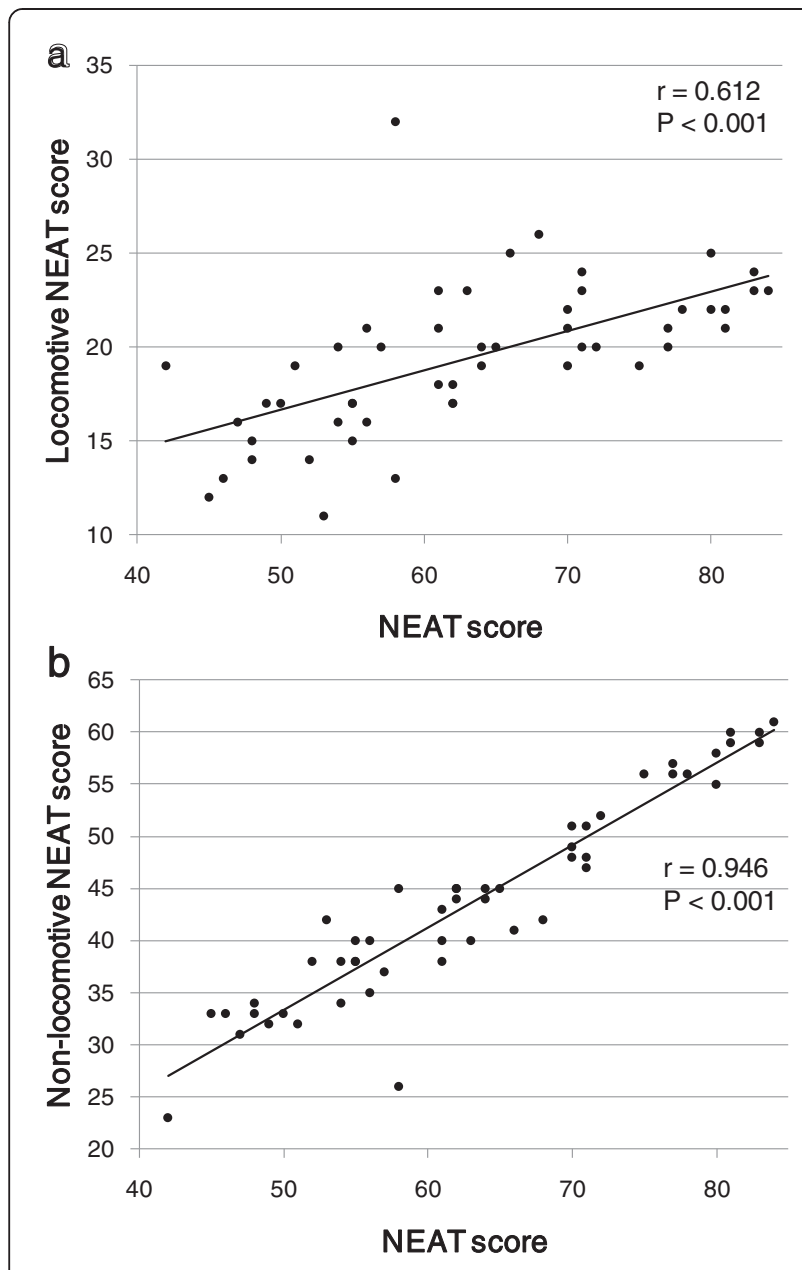

Figure 3 Correlations between the whole NEAT score and (a) the locomotive NEAT score and (b) the non-locomotive NEAT score.

\section{Discussion}

In the present study, we compared daily PA measured by the triaxial accelerometer with our original NEAT score. To our knowledge, our NEAT questionnaire is the first to evaluate NEAT including locomotive and nonlocomotive activities in clinical practices. Our findings showed that the NEAT scores measured by using our questionnaire were highly correlated with PAL measured by the triaxial accelerometer in Japanese patients with type 2 diabetes. Although the NEAT score obtained from the questionnaire is practical and cost-effective to evaluate PA, they are subjective data and may not always represent the true NEAT $[13,14]$. The accelerometry technique have been found to have a significant correlation with EE measured by the indirect calorimetry, therefore, it has been extensively considered to be a validated method for evaluating PA under free living conditions [9,15-18]. In the present study, the validity of our original NEAT questionnaire was confirmed by using the triaxial accelerometer.

Cooper AR et al. have showed that sedentary time was positively associated with metabolic risks [19], whereas the moderate-to-vigorous-intensity physical activity (MVPA) was associated with reduced metabolic risks [20]. Patients with type 2 diabetes generally show low levels of PA and have difficulty maintaining the recommended PAL $[21,22]$. The promotion of light-intensity daily PA such as NEAT is more practical and realizable as compared with the promotion of MVPA in the management of type 2 diabetes. We have previously demonstrated that the NEAT score determined by our original questionnaire is favorably associated with insulin sensitivity, abdominal obesity, lipid metabolism and blood pressure in patients with type 2 diabetes [7]. Taking account of present results, the promotion of NEAT may be useful for the management of type 2 diabetes.

We had unsolved things about the NEAT questionnaire in our previous study. The NEAT scores measured by questionnaire were more significantly and beneficially correlated with metabolic parameters in women as compared with those in men [7]. Briefly, the NEAT score was inversely associated with waist circumference, and also was positively associated with HDL-C level in women. However, a beneficial association of NEAT with waist circumference and HDL-C was not observed in men. Our NEAT questionnaire consists of 11 question items about locomotive activities such as walking and going up stairs, and 25 question items about non-locomotive activities such as washing dishes, ironing and sewing, and 21 question items are related to housework. Therefore, our

Table 3 Correlations of NEAT score with physiological and biochemical parameters in all participants, men and women

\begin{tabular}{|c|c|c|c|c|c|c|}
\hline & \multicolumn{2}{|c|}{ All participants $(n=45)$} & \multicolumn{2}{|c|}{ Men $(n=23)$} & \multicolumn{2}{|c|}{ Women $(n=22)$} \\
\hline & $r$ & $P$ value & $r$ & $P$ value & $r$ & $P$ value \\
\hline Waist circumference & -0.013 & 0.944 & 0.460 & 0.055 & -0.509 & 0.044 \\
\hline Systolic blood pressure & 0.184 & 0.226 & 0.371 & 0.082 & -0.034 & 0.882 \\
\hline Diastolic blood pressure & -0.029 & 0.852 & 0.108 & 0.625 & -0.137 & 0.543 \\
\hline Triglycerides & -0.171 & 0.268 & -0.028 & 0.903 & -0.320 & 0.147 \\
\hline HDL cholesterol & 0.079 & 0.608 & -0.441 & 0.040 & 0.494 & 0.020 \\
\hline Serum insulin & -0.420 & 0.019 & -0.422 & 0.104 & -0.421 & 0.118 \\
\hline
\end{tabular}

$\mathrm{r}$ indicates correlation coefficient. HDL, high-density lipoprotein; NEAT, non-exercise activity thermogenesis. 
questionnaire can evaluate non-locomotive activities adequately, however, may underestimate locomotive activities. The NEAT score of non-locomotive activities was more strongly correlated with the whole NEAT scores as compared with that of locomotive activities, supporting that our NEAT questionnaire is more excellent to evaluate non-locomotive activities such as housework as compared with locomotive activities such as walking. This may cause different effects of NEAT on metabolic parameters between men and women.

We have to mention the limitations of this study. We might overestimate or underestimate PA in the questionnaire. $\mathrm{EE}$ was estimated by regression equation assessed by the triaxial accelerometer. Leenders et al. indicated that the predictive equations based on the relationship between acceleration and EE during locomotive movements led to under- and overestimation of TEE [23]. It is possible that EE and PAL measured by the triaxial accelerometer differ from the true amount. For example, the accelerometer was worn on the left side of the waist and the movements of upper extremities could not be measured completely. The movement of upper extremities contributed less to EE than whole body trunk movements [24], however, our NEAT questionnaire included PA of upper extremities such as washing dishes, ironing and sewing, EE by those activities might have been underestimated.

\section{Conclusion}

We confirmed the validity of NEAT questionnaire by investigating the correlation of the NEAT score to PAL measured by the triaxial accelerometer. Our original NEAT questionnaire may be useful for evaluation of daily PAL in clinical practices.

\section{Additional file}

\section{Additional file 1: Non-Exercise Activity Thermogenesis (NEAT) score.}

\section{Competing interests}

The authors declare that they have no competing interests.

\section{Authors' contributions}

All five authors have substantially contributed to conception and design, acquisition of data or analysis and interpretation of data; drafting the article or revising it critically for important intellectual content; and all authors read and approved the final manuscript.

\footnotetext{
Acknowledgments

This study was supported by a grant from the National Center for Global Health and Medicine (25-203). The authors would like to thank Tomoko Kaga, Yukari Takano, Fumi Kawasaki, Yukie Kawamura, and Naomi Inoue at Clinical Research Center, National Center for Global Health and Medicine Kohnodai Hospital, for their technical help.

\section{Author details}

'Department of Internal Medicine, National Center for Global Health and Medicine Kohnodai Hospital, Chiba, Japan. ${ }^{2}$ Division of Complementary
}

Medicine, First Department of General Medicine, Saitama Medical Center, Jichi Medical University School of Medicine, Saitama, Japan. ${ }^{3}$ Department of Diabetes Research, Diabetes Research Center, National Center for Global Health and Medicine, Tokyo, Japan. ${ }^{4}$ Department of Human Health and Design, Faculty of Human Life and Environmental Sciences, Showa Women's University, Tokyo, Japan

Received: 11 March 2014 Accepted: 1 July 2014

Published: 5 July 2014

\section{References}

1. Thompson PD, Buchner D, Pina IL, Balady GJ, Williams MA, Marcus BH, Berra K, Blair SN, Costa F, Franklin B, Fletcher GF, Gordon NF, Pate RR, Rodriguez BL, Yancey AK, Wenger NK, American Heart Association Council on Clinical Cardiology Subcommittee on Exercise, Rehabilitaion, and Prevention: Exercise and physical activity in the prevention and treatment of atherosclerotic cardiovascular disease: a statement from the Council on Clinical Cardiology (Subcommittee on Exercise, Rehabilitaion, and Prevention) and the Council on Nutrition, Physical Activity, and Metabolism (Subcommittee on Physical Activity). Circulation 2003, 107:3109-3116.

2. Kodama S, Tanaka S, Heianza Y, Fujihara K, Horikawa C, Shimano H, Saito K Yamada N, Ohashi Y, Sone H: Association between physical activity and risk of all-cause mortality and cardiovascular disease in patients with diabetes: a meta-analysis. Diabetes Care 2013, 36:471-479.

3. Shibata A, Oka K, Harada K, Nakamura Y, Muraoka I: Psychological, social, and environmental factors to meeting physical activity recommendations among Japanese adults. Int J Behav Nutr Phys Act 2009, 6:60.

4. Levine JA: Non-exercise activity thermogenesis (NEAT). Nutr Rev 2004, 5:S82-S97.

5. Healy GN, Dunstan DW, Salmon J, Cerin E, Shaw JE, Zimmet PZ, Owen N: Objectively measured light-intensity physical activity is independently associated with 2-h plasma glucose. Diabetes Care 2007, 30:1384-1389.

6. Healy GN, Wijndaele K, Dunstan DW, Shaw JE, Salmon J, Zimmet PZ, Owen N Objectively measured sedentary time, physical activity, and metabolic risk: the Australian Diabetes, Obesity and Lifestyle Study (AusDiab). Diabetes Care 2008, 31:369-371.

7. Hamasaki H, Yanai H, Mishima S, Mineyama T, Yamamoto-Honda R, Kakei M, Ezaki O, Noda M: Correlations of non-exercise activity thermogenesis to metabolic parameters in Japanese patients with type 2 diabetes. Diabetol Metab Syndr 2013, 5:26.

8. Oshima Y, Kawaguchi K, Tanaka S, Ohkawara K, Hikihara Y, Ishikawa-Takata K, Tabata I: Classifying household and locomotive activities using a triaxial accelerometer. Gait Posture 2010, 31:370-374.

9. Ohkawara K, Oshima Y, Hikihara Y, Ishikawa-Takata K, Tabata I, Tanaka S: Real-time estimation of daily physical activity intensity by a triaxial accelerometer and a gravity-removal classification algorithm. $\mathrm{Br} J$ Nutr 2011, 105:1681-1691.

10. Ganpule AA, Tanaka S, Ishikawa-Takata K, Tabata I: Interindividual variability in sleeping metabolic rate in Japanese subjects. Eur J Clin Nutr 2007, 61:1256-1261

11. Energy and protein requirements: Report of a joint FAO/WHO/UNU expert consultation. World Health Organ Tech Rep Ser 1985, 724:1-206.

12. Ainsworth BE, Haskell WL, Herrmann SD, Meckes N, Bassett DR Jr. Tudor-Locke C, Greer JL, Vezina J, Whitt-Glover MC, Leon AS: Compendium of physical activities: a second update of codes and MET values. Med Sci Sports Exerc 2011, 43:1575-1581.

13. Colbert $L H$, Matthews $C E$, Havighurst TC, Kim K, Schoeller DA: Comparative validity of physical activity measures in older adults. Med Sci Sports Exerc 2011, 43:867-876.

14. Colbert LH, Schoeller DA: Expending our physical activity (measurement) budget wisely. J Appl Physiol 2011, 111:606-607.

15. Welk GJ, Corbin CB, Dale D: Measurement issues in the assessment of physical activity in children. Res Q Exerc Sport 2000, 71:S59-S73.

16. Midorikawa T, Tanaka S, Kaneko K, Koizumi K, Ishikawa-Takata K, Futami Tabata I: Evaluation of low-intensity physical activity by triaxial accelerometry. Obesity 2007, 15:3031-3038.

17. Plasqui $G$, Bonomi AG, Westerterp KR: Daily physical activity assessment with accelerometers: new insights and validation studies. Obes Rev 2013, 14:451-462. 
18. Ekelund U, Sjöström M, Yngve A, Poortvliet E, Nilsson A, Froberg K, Wedderkopp N, Westerterp K: Physical activity assessed by activity monitor and doubly labeled water in children. Med Sci Sports Exerc 2001, 33:275-281.

19. Cooper AR, Sebire S, Montgomery AA, Peters TJ, Sharp DJ, Jackson N, Fitzsimons K, Dayan CM, Andrews RC: Sedentary time, breaks in sedentary time and metabolic variables in people with newly diagnosed type 2 diabetes. Diabetologia 2012, 55:589-599.

20. Rennie KL, McCarthy N, Yazdgerdi S, Marmot M, Brunner E: Association of the metabolic syndrome with both vigorous and moderate physical activity. Int J Epidemiol 2003, 32:600-606.

21. Jakicic JM, Gregg E, Knowler W, Kelley DE, Lang W, Miller GD, Pi-Sunyer FX, Regensteiner JG, Rejeski WJ, Ridisl P, Walkup MP, Wolf DL: Activity patterns of obese adults with type 2 diabetes in the look AHEAD study. Med Sci Sports Exerc 2010, 42:1995-2005.

22. Morrato EH, Hill JO, Wyatt HR, Ghushchyan V, Sullivan PW: Physical activity in U.S. adults with diabetes and at risk for developing diabetes, 2003. Diabetes Care 2007, 30:203-209.

23. Leenders NY, Sherman WM, Nagaraja HN: Energy expenditure estimated by accelerometry and doubly labeled water: do they agree? Med SC Sports Exerc 2006, 38:2165-2172.

24. Kumahara H, Tanaka H, Schutz Y: Daily physical activity assessment: what is the importance of upper limb movements vs whole body movements? Int J Obes Relat Metab Disord 2004, 28:1105-1110.

doi:10.1186/2052-1847-6-27

Cite this article as: Hamasaki et al.: The validity of the non-exercise activity thermogenesis questionnaire evaluated by objectively measured daily physical activity by the triaxial accelerometer. BMC Sports Science, Medicine, and Rehabilitation 2014 6:27.

\section{Submit your next manuscript to BioMed Central and take full advantage of:}

- Convenient online submission

- Thorough peer review

- No space constraints or color figure charges

- Immediate publication on acceptance

- Inclusion in PubMed, CAS, Scopus and Google Scholar

- Research which is freely available for redistribution 